\title{
MicroRNA-33a-mediated downregulation of Pim-3 kinase expression renders human pancreatic cancer cells sensitivity to gemcitabine
}

\author{
Chen Liang ${ }^{1}$, Xian-Jun $\mathbf{Y u}^{2}$, Xiao-Zhong Guo ${ }^{3}$, Meng-Hong Sun ${ }^{4}$, Zhen Wang ${ }^{1}$, \\ Yao Song ${ }^{5}$, Quan-Xing Ni ${ }^{2}$, Hong-Yu Li ${ }^{3}$, Naofumi Mukaida ${ }^{5}$, Ying-Yi Li ${ }^{1,5}$ \\ ${ }^{1}$ Cancer Research Institute, Fudan University Shanghai Cancer Center, Department of Oncology, Shanghai Medical College, \\ Fudan University, Shanghai, China \\ ${ }^{2}$ Department of Pancreas and Hepatobiliary, Pancreatic Cancer Institute, Fudan University Shanghai Cancer Center, \\ Department of Oncology, Shanghai Medical College, Fudan University, Shanghai, China \\ ${ }^{3}$ Department of Gastroenterology, General Hospital of Shenyang Military Area, Shenyang, Liaoning, China \\ ${ }^{4}$ Department of Pathology, Fudan University Shanghai Cancer Center, Department of Oncology, Shanghai Medical College, \\ Fudan University, Shanghai, China \\ ${ }^{5}$ Division of Molecular Bioregulation, Cancer Microenvironment Research Program, Cancer Research Institute, Kanazawa \\ University, Kanazawa, Japan
}

Correspondence to:

Ying-Yi Li, e-mail: liyingyi@fudan.edu.cn

Keywords: miR-33a, serine/threonine kinase, tumor suppressor, chemoresistance, pancreatic cancer

Received: January 09, $2015 \quad$ Accepted: April 25, $2015 \quad$ Published: May 08, 2015

\section{ABSTRACT}

Pancreatic ductal adenocarcinoma (PDAC) is one of the most lethal cancers, with less than $5 \%$ of patients surviving 5 years beyond diagnosis. Systemic therapies, particularly gemcitabine, have a modest clinical benefit, but chemoresistance limits their efficacy. Here, we demonstrate that plasma miR-33a levels positively correlated with miR-33a levels in tumor tissues of patients with PDAC and are a good prognostic indicator of overall survival. Overexpression of miR-33a inhibited tumor cell proliferation and increased the chemosensitivity to gemcitabine both in vitro and in vivo. Moreover, miR-33a targets Pim-3 directly in PDAC. Pim-3 expression was a prognostic indicator related to poor survival in pancreatic cancer patients. Plasma miR-33a levels were significantly lower in pancreatic cancer patients with high Pim-3 protein expression than in healthy controls. Furthermore, overexpression of miR-33a in pancreatic cancer cell lines suppressed Pim-3 expression, leading to downregulation of the AKT/Gsk-3 $\beta / \beta$-catenin pathway. Overall, these results indicate that miR-33a functions as a tumor suppressor that downregulates Pim-3 kinase expression to inhibit both pancreatic tumor growth and gemcitabine resistance via the AKT/ $\beta$-catenin pathway. Hence, detection of plasma miR-33a may be a simple and convenient method of predicting therapeutic responses.

\section{INTRODUCTION}

Pancreatic ductal adenocarcinoma (PDAC) is one of the most deadly human malignant neoplasms and the fourth leading cause of cancer-related deaths in the United States [1]. With an overall 5 year survival rate $<5 \%$ and a median survival of $<1$ year, pancreatic cancer has an extremely poor prognosis [2]. Gemcitabine, which has been available for more than a decade, is the only first-line chemotherapeutic agent used for the palliative treatment of patients with PDAC [3]. However, the tumors in a substantial number of patients are already (or rapidly become) chemoresistant to gemcitabine [2]. Recent studies identified several chemoresistant mechanisms associated with the metabolism and molecular targets of gemcitabine $[4,5]$. Combining gemcitabine with a targeted therapeutic strategy may be beneficial for the treatment of gemcitabine-refractory pancreatic cancer. 
MicroRNAs (miRNAs) are a class of singlestranded, small, noncoding RNAs that regulate gene expression by interfering with specific mRNAs at the post-transcriptional level [6]. By regulating the expression of cancer-specific genes, miRNAs can function as either oncogenes or tumor suppressors [7, 8]. Dysregulated miRNAs are associated with PDAC proliferation, invasion, chemosensitivity, and prognosis [9]. A more complete understanding of the unique patterns of dysregulated miRNAs in PDAC may identify potential therapeutic targets or molecular biomarkers and improve tumor diagnosis or predictions of therapeutic responses.

Previous studies examined the contributions of miRNAs to pancreatic carcinogenesis and diagnosis. For example, let-7 expression is significantly lower in pancreatic cancer cells than in normal acinar pancreatic tissue; restoration of let-7 expression inhibits cell proliferation, K-ras expression, and mitogen-activated protein kinase activation, but does not inhibit tumor growth after intratumoral gene transfer [10]. Moreover, miR-34 restores the tumor-suppressive function of p53 in p53-deficient human pancreatic cancer cells by modulating downstream Notch signaling and Bcl-2; it also plays an important role in self-renewal of pancreatic cancer cells [11]. By contrast, miR-21 is upregulated in pancreatic cancer cells, where it targets PTEN, PDCD4, TPM1, and TMP3, leading to the inhibition of apoptosis [12].

Pim-3, a member of the proto-oncogene Pim family, exhibits serine/threonine kinase activity [13] and has high sequence similarity to Pim-1 and Pim-2 [14]. We previously showed that Pim-3 protein expression is increased in premalignant and malignant lesions of endoderm-derived organs such as the pancreas, colon, liver, and stomach, whereas it is expressed at barely detectable levels in these normal adult organs [15]. Moreover, Pim-3 regulates tumor cell proliferation, survival, and apoptosis during early carcinogenesis $[16,17]$. A recent study demonstrated that inhibiting Pim-3 kinase sensitizes pancreatic cancer cells to gemcitabine [18]. However, the precise mechanisms by which signaling responses contribute to Pim-3-mediated pancreatic carcinogenesis and chemoresistance remain to be elucidated.

Here, we showed that miR-33a acts as an important suppressor of human pancreatic cancer by directly regulating Pim-3 expression at the post-transcriptional level. Overexpression of miR-33a led to a marked downregulation of Pim-3 expression, thereby inhibiting AKT/Gsk-3 $\beta / \beta$-catenin signaling, which in turn reduced cell proliferation and increased the chemosensitivity of pancreatic cancer cells to gemcitabine both in vitro and in vivo. The results suggest that the plasma level of miR-33a may be a valuable biomarker and an important prognostic factor for human pancreatic cancer.

\section{RESULTS}

\section{Plasma miR-33a expression is positively correlated with tissue miR-33a expression and an improved prognosis for patients with pancreatic cancer}

MiR-33a expression is associated with an improved prognosis for PDAC [19]. Therefore, we first examined miR-33a levels in the plasma of 106 PDAC patients and 100 healthy controls. We found that plasma miR-33a levels were higher in healthy controls than in PDAC patients (Figure 1A). Low plasma miR-33a levels were significantly associated with tumor size $(P=0.0381$; Table 1). A Kaplan-Meier analysis indicated that low levels of plasma miR-33a led to a significant reduction in the overall survival of 79 PDAC patients (Figure 1B). Moreover, in situ hybridization detected visible and gradable expression of miR-33a in tissue samples from the 106 PDAC patients (Figure 1C). Also, miR-33a levels in the plasma positively correlated with miR-33a levels in the pancreatic tumors of the 106 patients (Figure 1D).

\section{MiR-33a inhibits cell proliferation and increases the chemosensitivity of human pancreatic cancer cells to gemcitabine both in vitro and in vivo}

Since the poor prognosis for PDAC is due in part to chemoresistance [2], we next examined the relationship between miR-33a and gemcitabine resistance in vitro. Stable expression of miR-33a in the SW1990 and MiaPaca-2 pancreatic cancer cell lines (SW1990-miR-33a and Mia-2-miR-33a) led to a significant reduction in growth (Figure 2A) and in the $\mathrm{IC}_{50}$ value of gemcitabine for SW1990 and MiaPaca-2 cells (Table 2). In addition, overexpression of miR-33a increased the sensitivity of both cell lines to gemcitabine in a dose- and time-dependent manner (Figure 2B and 2C). To assess the function of miR-33a in vivo, SW1990 or SW1990-miR-33a cells were subcutaneously implanted into nude mice. Tumor growth in the gemcitabinetreated SW1990-miR-33a group was slower than that in the PBS-treated and gemcitabine-treated SW1990 groups (Figure 2D). Furthermore, overexpression of miR-33a in gemcitabine-treated SW1990 cells resulted in fewer tumors in these mice (Figure 2E). Similar results were obtained using mice injected with MiaPaca-2 and Mia-2-miR-33a cells (Supplementary Figure 1A and 1B). There was a significant negative correlation between xenograft size and miR-33a expression (Figure 2F; $r=-0.8974, P=0.0153$ ), indicating that miR-33a negatively regulates tumor volume by increasing the chemosensitivity of pancreatic cancer cells to gemcitabine. In addition, immunohistochemical analyses revealed that 
A

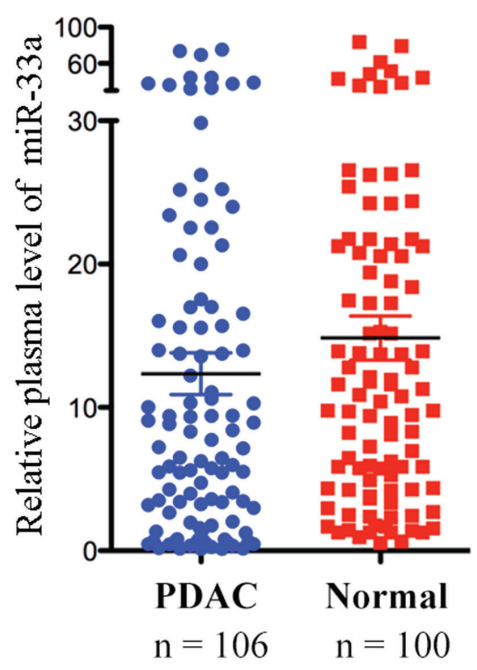

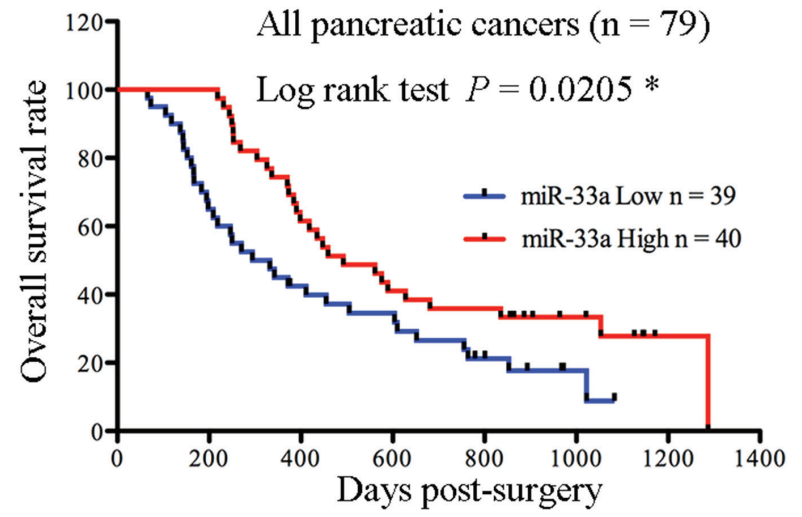

C

Low

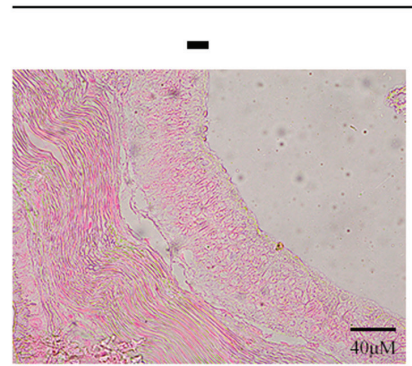

\section{$+$}

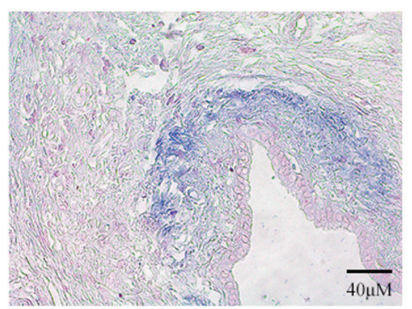

High

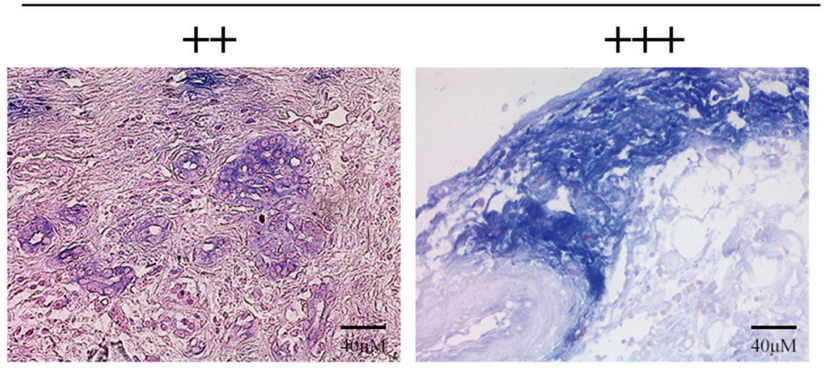

D

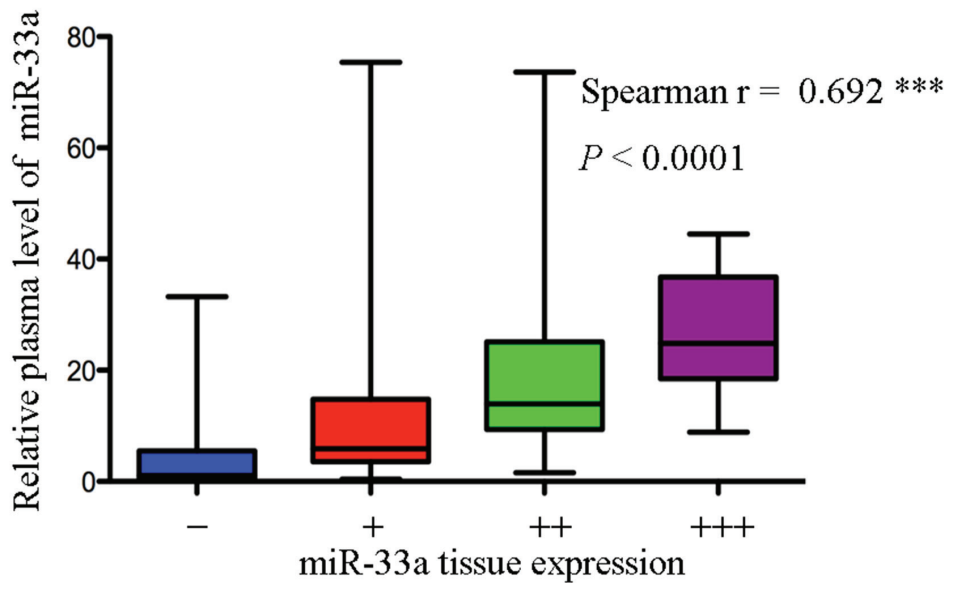

Figure 1: MiR-33a expression is reduced in plasma and tumor tissues from pancreatic cancer patients and is a prognostic indicator for pancreatic cancer. A. Comparison of miR-33a expression levels in plasma from pancreatic cancer patients and healthy controls. The expression levels of miR-33a were determined by qRT-PCR and normalized to those of cel-miR-39. The horizontal line represents the median value, and the error bars indicate the SEM. B. Overall survival analysis based on the expression levels of miR-33a in the plasma. C. miR-33a expression in serial sections of human pancreatic cancer tissues, as analyzed by in situ hybridization. The scoring criteria are described in the Materials and Methods. D. Positive correlation between the plasma and tumor tissue miR-33a levels in 106 PDAC patients (Spearman's $r=0.692,{ }^{* * *} P<0.001$ ). The ends of the whiskers represent the $1^{\text {st }}$ and $99^{\text {th }}$ percentiles. 
Table 1: Correlation between plasma miR-33a expression and the clinicopathological features of 106 PDAC specimens

\section{No. of cases}

\section{Age}

$$
\leq 62 \text { years }
$$

$>62$ years

54

52

\section{Gender}

Male

Female

49

Tumor Location

$\begin{array}{ll}\text { Head } & 54 \\ \text { Body and Tail } & 52\end{array}$

Tumor Size

$\leq 4 \mathrm{~cm}$

$>4 \mathrm{~cm}$

54

52

71

35

Nodal Metastasis

$\mathrm{N}_{0}$
$\mathrm{~N}_{1}-\mathrm{N}_{3}$

Tumor Differentiation

Well or Moderate

Poor

72

34

TNM Stage

$\begin{array}{ll}\text { I and II } & 83 \\ \text { III and IV } & 23\end{array}$

\author{
No. of patients (\%) \\ miR-33a High \\ miR-33a Low
}

$$
\begin{aligned}
& 27(50.0 \%) \\
& 26(50.0 \%)
\end{aligned}
$$

$$
\begin{aligned}
& 27(50.0 \%) \\
& 26(50.0 \%)
\end{aligned}
$$

1.0000

$P$-value

$$
\begin{aligned}
& 34(59.6 \%) \\
& 19(38.8 \%)
\end{aligned}
$$

$$
\begin{aligned}
& 23(40.4 \%) \\
& 30(61.2 \%)
\end{aligned}
$$

$$
27(50.0 \%)
$$

$27(50.0 \%)$

$26(50.0 \%)$

$$
26(50.0 \%)
$$

$$
41(57.7 \%)
$$

$12(34.3 \%)$

$30(42.3 \%)$

$23(65.7 \%)$

$0.0381 *$

$31(50.0 \%)$

$31(50.0 \%)$

$22(50.0 \%)$

$22(50.0 \%)$

1.0000

$$
\begin{array}{ll}
37(51.4 \%) & 35(48.6 \%) \\
16(47.1 \%) & 18(52.9 \%)
\end{array}
$$

0.8354
$40(48.2 \%)$
$43(51.8 \%)$
$13(56.5 \%)$

0.6381 stable expression of miR-33a acted synergistically with gemcitabine to reduce the number of proliferating Ki67positive cells (Figure $2 \mathrm{G}$ and $2 \mathrm{H}$ ).

\section{MiR-33a reverses the chemoresistance of human pancreatic cancer cells to gemcitabine both in vitro and in vivo}

To confirm the hypothesis that miR-33a is involved in chemoresistance of PDAC, we established stable SW1990 and MiaPaca-2 cell lines that were resistant to gemcitabine (SW1990-res and Mia-2-res); the resistance indices (RI) for these cell lines were 215 (95\% CI, 195.27234.73) and 173.1 (95\% CI, 165.95-180.25), respectively (Table 2). Notably, the resistant cells expressed low levels of miR-33a (Figure 3A), and their growth rates were higher than those of the corresponding parental cell lines
(Figure 3B). To determine whether overexpression of miR-33a reverses gemcitabine resistance, miR-33a was stably expressed in SW1990-res and Mia-2-res cells to generate SW1990-res-miR-33a and Mia-2-res-miR-33a cells, respectively. We observed that overexpression of miR-33a led to a significant reduction in the growth rate of the resistant cell lines (Figure 3B). Moreover, overexpression of miR-33a reduced the $\mathrm{IC}_{50}$ value of gemcitabine towards the resistant cells (Table 2) and reduced cell viability in both a dose- and time-dependent manner (Figure 3C and 3D). Furthermore, overexpression of miR-33a in SW1990-res cells repressed tumor growth and reduced resistance to gemcitabine in vivo (Figure 3E). Similarly, overexpression of miR-33a in Mia-2-res cells reduced the tumor mass (Supplementary Figure 2). There was a significant negative correlation between xenograft size and miR-33a expression in mice 
A
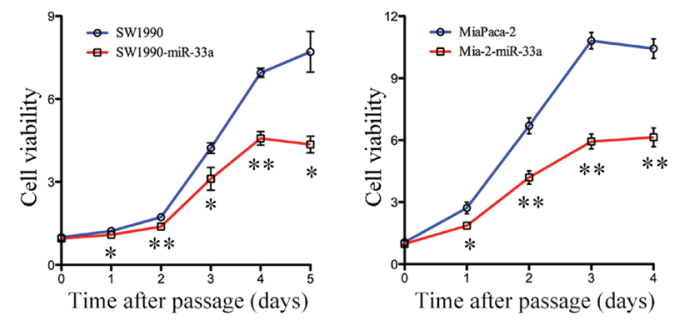

B

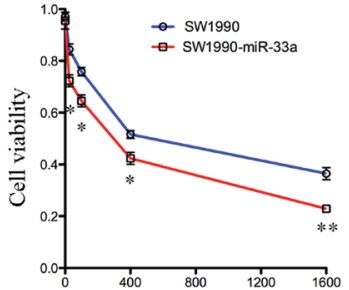

GEM concentration (nM)

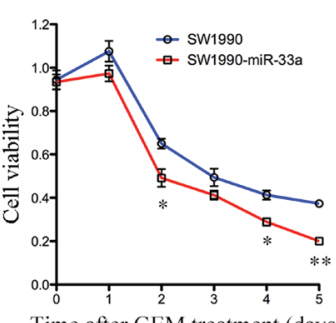

Time after GEM treatment (days)
C

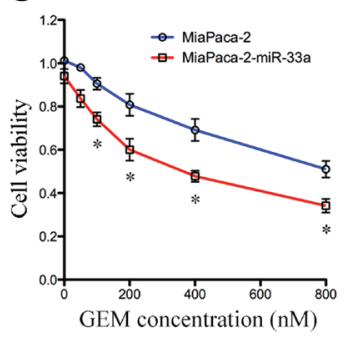

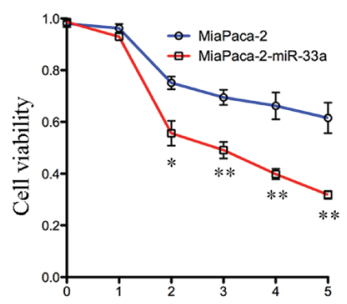

Time after GEM treatment (days)
D

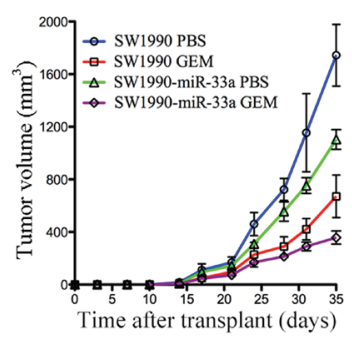

$\mathbf{E}$

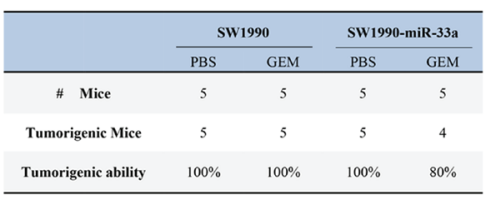

F

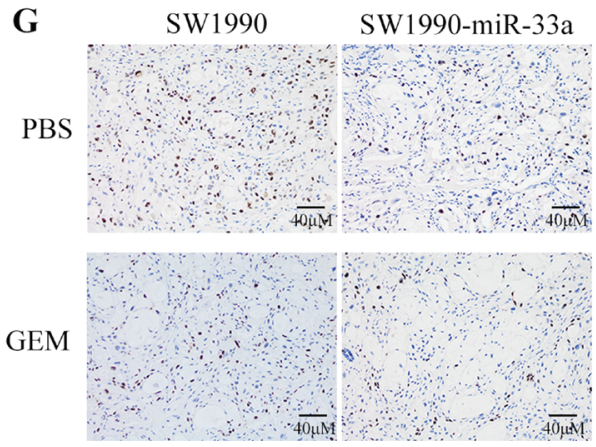

H

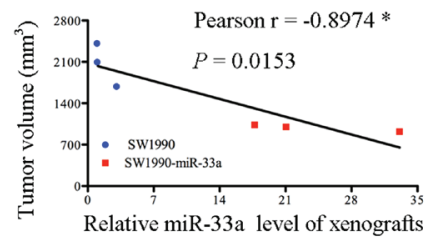

Figure 2: Overexpression of miR-33a increases the chemosensitivity of human pancreatic cancer cells to gemcitabine both in vitro and in vivo. A. The effects of stable overexpression of miR-33a on pancreatic cancer cell viability. The cell numbers were determined at the indicated time intervals using Cell Counting Kit- 8 reagent and were normalized to those at time 0 . Data are expressed as the mean $+/-\mathrm{SD}$ of five replicates. The experiments were repeated three times, and representative results are shown. $* P<0.05$ and ${ }^{*} P<<0.01$. B, C. The effects of gemcitabine (GEM) on the viability of SW1990-miR-33a (B) and Mia-2-miR-33a (C) cells and their parental cells. The cells were treated with increasing concentrations of GEM for $48 \mathrm{~h}$ (B and C, left panel) or with $200 \mathrm{nM}$ GEM [SW1990 cells] (B, right panel) or $350 \mathrm{nM}$ GEM [MiaPaca-2 cells] (C, right panel) for $0-5$ days. Cell numbers were determined using Cell Counting Kit- 8 as described in the Materials and Methods. The results are expressed as the mean $+/-$ SD of five replicates from three independent experiments. ${ }^{*} P<0.05$ and ${ }^{* *} P<0.01$. D. Size of tumors in mice that received subcutaneous implants of SW1990-miR-33a cells or parental cells. The mice were treated with GEM or PBS (control), and tumor growth was measured twice per week. The data are expressed as the mean $+/-$ SD. E. Tumor formation in the mice described in (D) on Day 35. F. Negative correlation between the volume of the xenograft tumors and miR-33a expression (Pearson's $r=-0.8974, P=0.0153$ ). G. Immunohistochemical analyses of Ki67-positive cells in tumor xenograft samples from mice treated with GEM or PBS. Magnification, $\times 400$. H. The number of Ki67-positive cells per field (five randomly selected visual fields) at $400 \times$ magnification. Data are expressed as the mean $+/-$ SD of three samples per group. ${ }^{*} P<0.05$, $* * P<0.01$, and $* * * P<0.001$. 
Table 2: The $\mathrm{IC}_{50}$ values for gemcitabine and the resistance indices of pancreatic cancer cells

\begin{tabular}{|c|c|c|c|c|c|}
\hline Cell lines & $\mathrm{IC}_{50}$ & $\mathbf{R I}$ & Cell lines & $\mathrm{IC}_{50}$ & RI \\
\hline SW1990 & $502.3 \pm 39.7 \mathrm{nM}$ & $215 \pm 19.73$ & MiaPaca-2 & $987.2 \pm 82.7 \mathrm{nM}$ & $173.1 \pm 7.15$ \\
\hline SW1990-miR-33a & $204.5 \pm 19.2 \mathrm{nM}^{* *}$ & & Mia-2-miR-33a & $336.5 \pm 41.0 \mathrm{nM}^{* *}$ & \\
\hline SW1990-res & $106.5 \pm 17.2 \mu \mathrm{M}$ & & Mia-2-res & $168.6 \pm 3.8 \mu \mathrm{M}$ & \\
\hline SW1990-res-miR-33a & $28.21 \pm 3.3 \mu \mathrm{M}^{\#}$ & & Mia-2-res-miR-33a & $61.9 \pm 10.1 \mu \mathrm{M}^{\# \#}$ & \\
\hline
\end{tabular}

Abbreviations: $\mathrm{IC}_{50}: 50 \%$ inhibitory concentration; $\mathrm{RI}$ : Resistance index.

${ }^{* *} P<0.01$ versus the parental cells; ${ }^{\#} P<0.05{ }^{{ }^{*}} P<0.001$ versus the resistant cells.

injected with SW1990-res cells (Figure 3F; $r=-0.8673$, $P=0.0253)$. After gemcitabine treatment, the tumor shrinkage ratio was most marked in mice that received xenografts of non-resistant cells stably overexpressing miR-33a (Supplementary Figure 3). In addition, stable expression of miR-33a reduced the number of proliferating Ki67-positive cells in SW1990-res tumors, and acted synergistically with gemcitabine to inhibit this parameter (Figure $3 \mathrm{G}$ and $3 \mathrm{H}$ ).

\section{MiR-33a directly targets the 3'UTR of Pim-3 in pancreatic cancer cell lines}

A previous study shows that miR-33a interact with Pim-1 in cancer cells [20]. Kinases belonging to the Pim family are highly homologous [14], suggesting that miRNAs that bind Pim-1 may also bind Pim-3 via a similar complementary sequence in the $3^{\prime} \mathrm{UTR}$ of the mRNA. To examine whether miR-33a bound to Pim-3, we performed in silico analyses of putative miRNA-binding sites in Pim-3 mRNA using different algorithms (www. ebi.ac.uk; www.microrna.org; and www.targetscan.org). A computational analysis (www.targetscan.org) revealed that miR-33a bound to a highly conserved sequence within the 3'UTR of Pim-3 that is conserved across different vertebrates (Figure 4A). Moreover, transfection of MiaPaca-2 and PCI55 pancreatic cancer cells with miR33 a mimics led to a significant reduction in the expression of Pim-3 protein, but not in Pim-3 mRNA expression (Figure 4B).

Drosophila AGO1, a component of the RNAinduced silencing complex, represses translation triggered by binding of miRNAs to imperfect complementary sites in the $3^{\prime}$ UTRs of their mRNA targets [21-23]. To determine whether miR-33amediated downregulation of Pim-3 requires AGO1, a RIP analysis was performed using an anti-AGO1 antibody or IgG (control). The amount of Pim-3 mRNA associated with AGO1 was significantly higher in MiaPaca-2 and PCI55 pancreatic cancer cells transfected with miR-33a mimics than in parental cells or cells transfected with negative control mimics (cel-miR-239b) (Figure 4C). However, no Pim-3 mRNA was detected in the $\mathrm{IgG}$ immunoprecipitates (data not shown). Next, to determine whether Pim-3 is a direct target of miR$33 \mathrm{a}$ in pancreatic cancer, PCI55 and MiaPaca-2 cells were co-transfected with the miRNA mimics together with a luciferase reporter plasmid containing the wildtype 3'UTR of Pim-3 or the same region harboring a mutation in the miR-33a seed sequence $\left(\Delta 3^{\prime} \mathrm{UTR}\right.$; Figure 4D). Co-transfection of both cell lines with the miR-33a mimics repressed the luciferase activity of the wild-type Pim-3 3'UTR construct, but not that of the Pim-3 $\triangle 3^{\prime}$ UTR construct or empty psiCHECK-2 vector (Figure 4E). Moreover, the luciferase activity of the wild-type Pim-3 3'UTR construct was not repressed by co-transfection of the cells with the cel-miR-239b mimics (Figure 4E). Furthermore, we also found that the expression levels of miR-33a in seven pancreatic cancer cell lines were negatively correlated with those of Pim-3 protein (Figure 4F and 4G; Spearman's $r=-0.79$, $P<0.05)$. Taken together, these results indicate that Pim-3 is a true target of miR-33a in pancreatic cancer cell lines.

\section{Pim-3 expression is negatively correlated with miR-33a expression and a poor prognosis}

To study the relationship between miR-33a and Pim-3 in pancreatic cancer, the expression levels of Pim-3 in tissue samples from 106 patients with PDAC were determined and graded by immunohistochemistry (Figure 5A). Pim-3 protein was expressed at high levels in $54.7 \%(58 / 106)$ of the pancreatic cancer tissues, and Kaplan-Meier analysis indicated that high Pim3 expression was associated with a poor prognosis in 79 pancreatic cancer patients (Figure 5B and 5C). Moreover, serial sections of the tissues revealed a negative correlation between miR-33a and Pim-3 expression (Figure 5C; $P<0.05$ ). Furthermore, the miR-33a levels in plasma samples from the 106 PDAC patients were negatively correlated with the levels of 
A

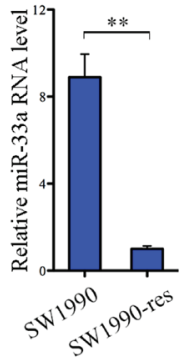

C

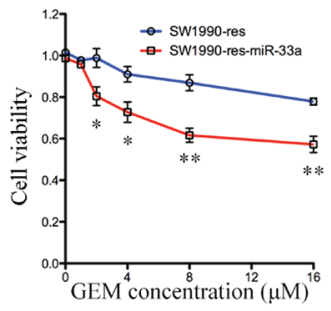

$\mathbf{E}$

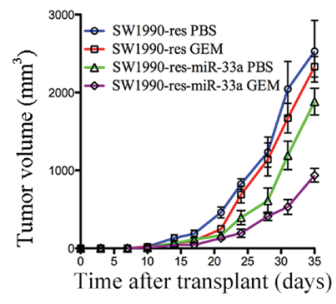

B
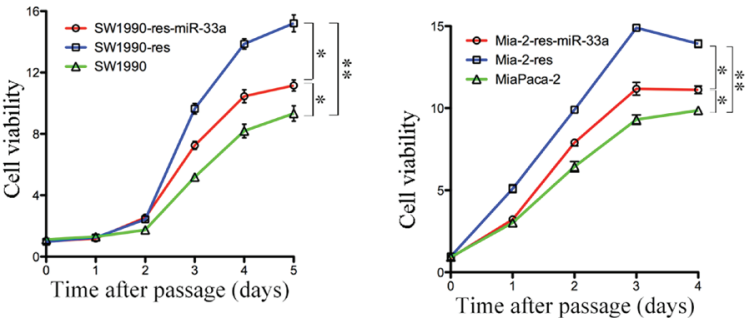

D
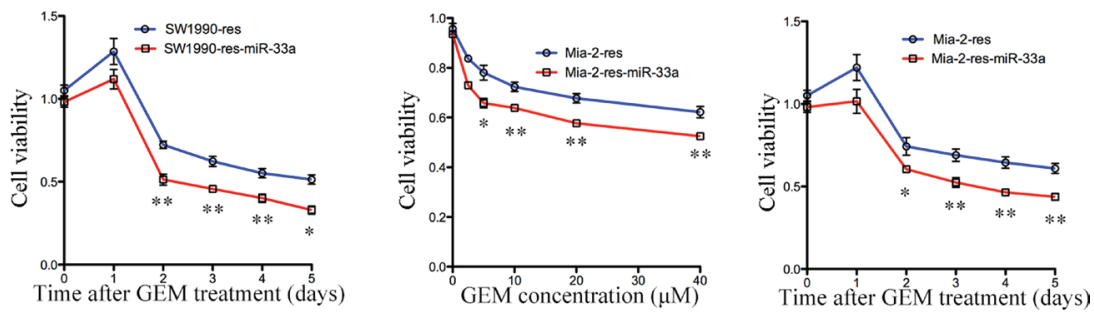

$\mathbf{F}$
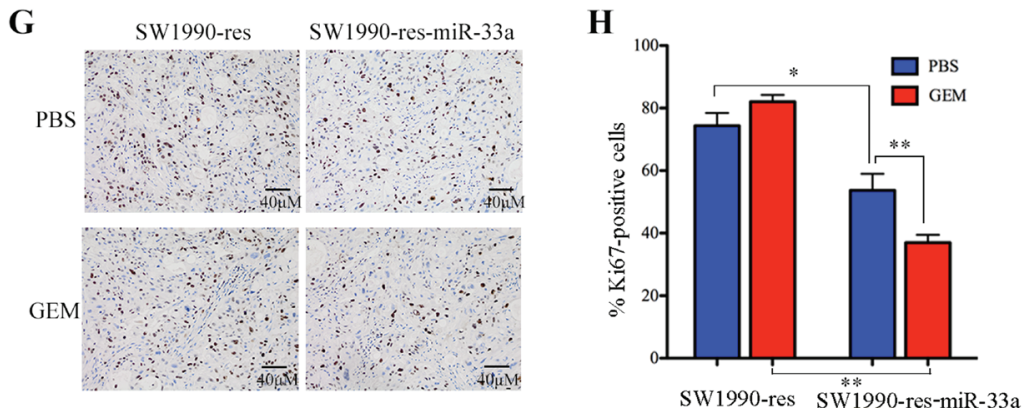

Figure 3: Overexpression of miR-33a reverses the chemoresistance of pancreatic cancer cells to gemcitabine both in vitro and in vivo. A. The expression levels of miR-33a in the indicated resistant and parental cell lines, as determined by $\mathrm{qRT}-\mathrm{PCR}$. Data are expressed as the mean $+/-$ SD of three independent experiments. ${ }^{*} P<0.01$. B. The effects of stable miR-33a expression on the viability of gemcitabine-resistant pancreatic cancer cells (Mia-2-res). Cell numbers were determined as the indicated time points using the Cell Counting Kit- 8 reagent, and the ratios were compared with that at time 0 . Data are expressed as the mean $+/-$ SD of five replicates. All experiments were repeated three times, and representative results are shown. ${ }^{*} P<0.05$ and $* * P<0.01$. C, D. The effects of gemcitabine (GEM) on the viability of SW1990-res-miR-33a (C) and Mia-2-res-miR-33a (D) cells and their parental resistant cell lines. The cells were treated with increasing concentrations of GEM for $48 \mathrm{~h}(\mathrm{C}$ and D, left panels) or with $30 \mu \mathrm{M}$ GEM [SW1990-res] (C, right panel) or $60 \mu \mathrm{M}$ GEM [Mia-res cells] (D, right panel) for 0-5 days. The cell numbers were determined using Cell Counting Kit-8, as described in the Materials and Methods. The results are expressed as the mean $+/-\mathrm{SD}$ of five replicates from three independent experiments. $* P<0.05$ and $* * P<0.01$. E. Size of tumors in mice that received subcutaneous implantations of SW1990-res-miR-33a cells or parental resistant cells. The mice were treated with GEM or PBS (control), and tumor growth was measured twice per week. Data are expressed as the mean $+/-$ SD. F. Negative correlation between the volume of xenograft tumors and the miR-33a expression level (Pearson's $r=-0.8673$, $P=0.0253)$. G. Immunohistochemical analyses of Ki67-positive cells in tumor xenograft samples from mice treated with GEM or PBS. Magnification, $\times 400$. H. The number of Ki67-positive cells per field (five randomly selected visual fields) at $400 \times$ magnification. Data are expressed as the mean $+/-\mathrm{SD}$ of three samples per group. ${ }^{*} P<0.05$ and $* * P<0.01$. 
A

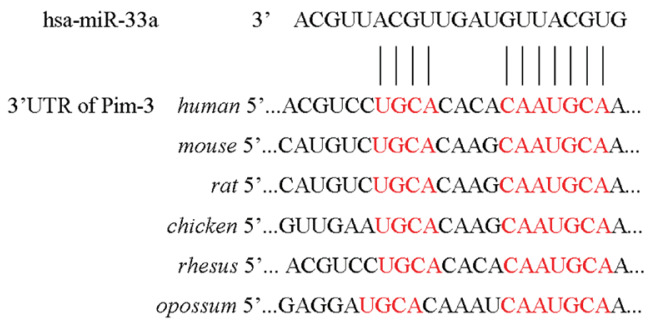

C

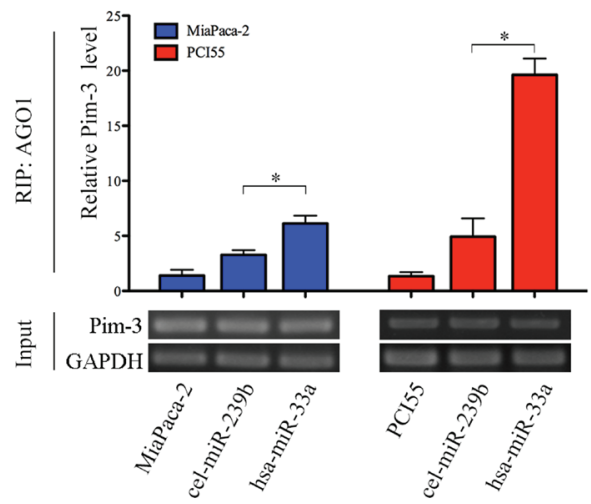

$\mathbf{F}$

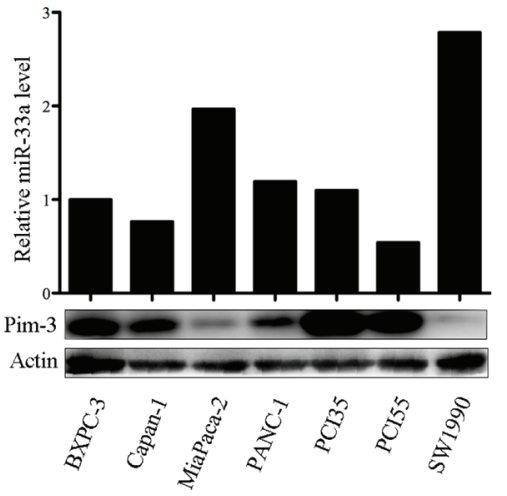

G
B
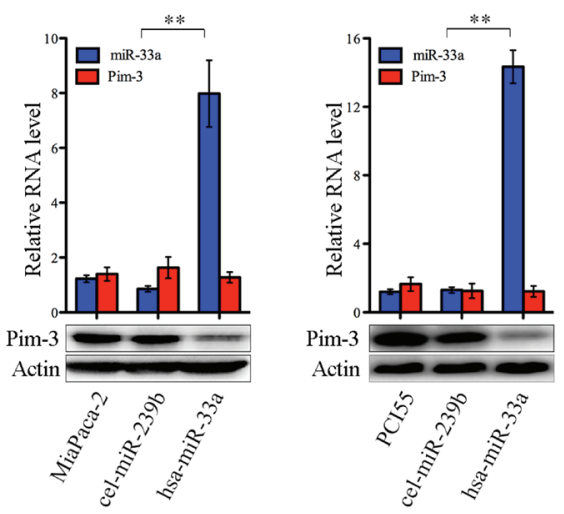

D

hsa-miR-33a 3' ACGUUACGUUGAUGUUACGUG

3'UTR of Pim-3 5'...ACGUCCUGCACACACAAUGCAA... $\triangle$ 3'UTR of Pim-3 5'...ACGUCCUGCACACACAUUCCUA...

$\mathbf{E}$
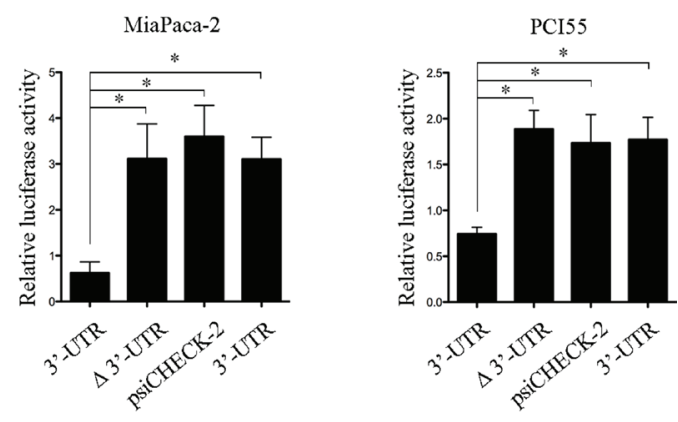

hsa-miR-33a cel-miR-239b

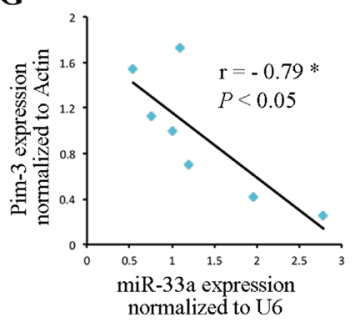

Figure 4: miR-33a suppresses Pim-3 expression by directly targeting its 3'UTR. A. Alignment of the miR-33a target sequences within the $3^{\prime}$ UTR of Pim-3 from different vertebrates. The seed match sequences are shown in red. B. qRT-PCR analyses of miR-33a and Pim-3 mRNA levels (top panel), and western blot analyses of Pim-3 protein levels (bottom panel) in MiaPaca-2 and PCI55 cells transfected with miR-33a (hsa-miR-33a) or with negative control (cel-miR-239b) mimics. The experiments were repeated three times, and representative results are expressed as the mean $+/-\mathrm{SD} . * * P<0.01$. C. RIP analyses of Pim-3 mRNA bound to AGO1 in MiaPaca-2 and PCI55 cells transfected with hsa-miR-33a or cel-miR-239b. Semi-quantitative PCR analyses of the input material (without immunoprecipitation) are also shown. GAPDH was used as a loading control. The experiments were repeated three times, and representative results are expressed as the mean $+/-\mathrm{SD} . * P<0.05$. D. Sequences of the wild-type and mutated $(\Delta)$ Pim-3 3 'UTRs in the luciferase reporter constructs used in $\mathbf{E}$. The asterisks indicate mutations in the miR-33a seed region. E. Relative luciferase activities of reporter constructs (psiCHECK-2) containing the wild-type or mutated Pim-3 3'UTR. MiaPaca-2 and PCI55 cells were co-transfected with reporter construct and hsa-miR-33a or cel-miR-239b. Renilla luciferase activity was determined $48 \mathrm{~h}$ after transfection and was normalized to that of constitutive firefly luciferase. The experiments were repeated three times, and representative results are expressed as the mean $+/-$ SD. ${ }^{*} P<0.05$. F. The expression levels of miR-33a and Pim-3 protein in various human pancreatic cancer cell lines, as determined by qRT-PCR (top panel) and western blot (bottom panel) analysis, respectively. The expression level of small nuclear RNA U6 was used to normalize the qRT-PCR results, and $\beta$-actin was used to ensure equal protein loading. G. Correlation between miR-33a and Pim-3 protein expression in human pancreatic cancer cell lines (Pearson's $r=-0.79, P<0.05$ ). 
Pim-3 in the pancreatic tumors (Figure 5D). Notably, plasma miR-33a levels in healthy controls were similar to those in pancreatic cancer patients with low Pim3 expression; however, plasma miR-33a levels were significantly lower in pancreatic cancer patients with high Pim-3 expression than in controls (Figure 5E).

\section{Downregulation of Pim-3 by miR-33a inhibits cell proliferation and chemoresistance, in part by activating the AKT/glycogen synthase kinase $3 \beta / \beta$-catenin cascade}

Stable expression of miR-33a in SW1990 and MiaPaca-2 pancreatic cancer cells (SW1990-miR-33a and Mia-2-miR-33a) led to a reduction in the level of Pim-3 protein but not that of mRNA (Figure 6A). Although a previous study showed that miR33a-mediated downregulation of cyclin-dependent kinase 6 (CDK6) reduces cell proliferation [20, 24], we found that overexpression of miR-33a did not downregulate CDK6 protein in SW1990 or MiaPaca-2 cells (Figure 6A), indicating that the effects on Pim-3 expression are specific to pancreatic cancer cells that we examined.

Pim-3 may be a novel regulator of AKT and $\mathrm{Wnt} / \beta$-catenin signaling [25]. Hence, we next examined whether overexpression of miR-33a reduces $\beta$-catenin levels in SW1990 and MiaPaca-2 cells. Overexpression of miR-33a failed to reduce the total amount of AKT protein. However, the levels of endogenous Pim-3, phospho-AKT, and phospho-glycogen synthase kinase $3 \beta$ (phospho-Gsk-3 $\beta$ ) were reduced markedly under these conditions, and these changes facilitated $\beta$-catenin destruction (Figure 6B). Transient transfection of SW1990-miR-33a and Mia-2-miR-33a cells with Pim-3 cDNA restored the amounts of phospho-AKT, phospho-Gsk-3 $\beta$, and $\beta$-catenin proteins, but did not affect the total amount of AKT protein (Figure 6B). Moreover, transfection with Pim-3 cDNA also rescued cell growth (Figure 6C) and restored resistance to gemcitabine (Figure 6D), both of which were inhibited by miR-33a overexpression. In accordance with the
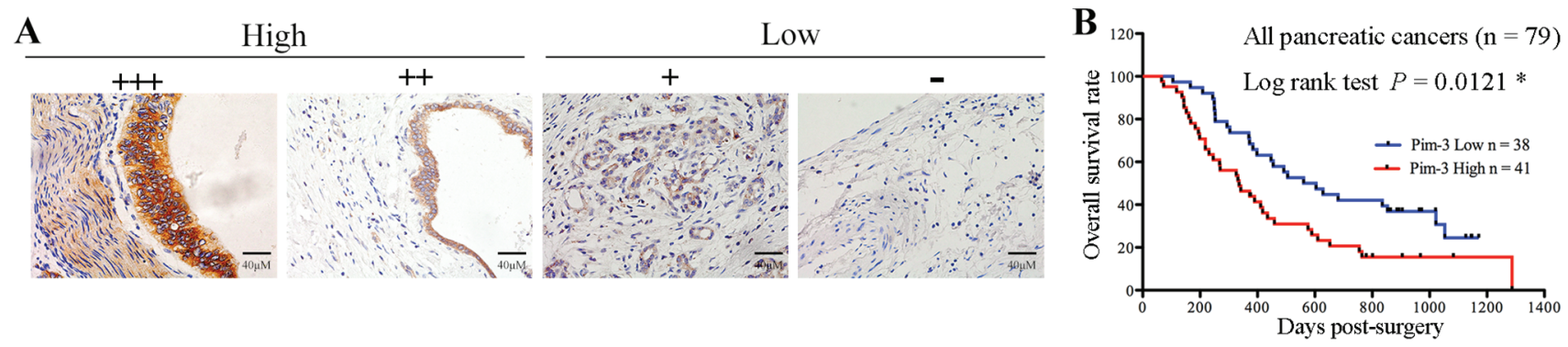

C

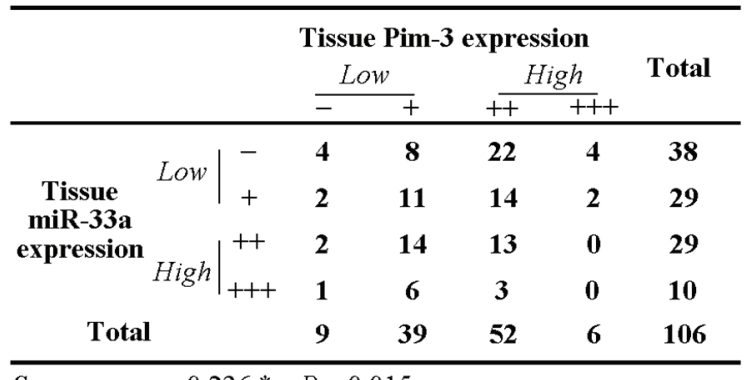

Spearman $\mathrm{r}=-0.236 * \quad P=0.015$
D

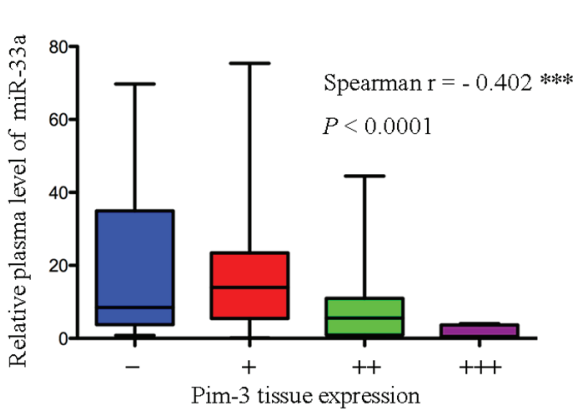

$\mathbf{E}$

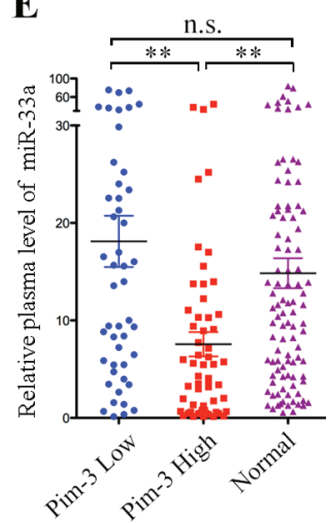

Figure 5: Pim-3 expression is inversely correlated with miR-33a expression. A. Pim-3 protein expression in serial sections of human pancreatic cancer tissues, as analyzed using immunohistochemistry. The scoring criteria are described in the Materials and Methods. B. Overall survival analysis based on the expression levels of Pim-3 in the tumor tissue. C. Summary of the miR-33a and Pim-3 expression levels in 106 pancreatic ductal adenocarcinoma tissues. The negative correlation between the expression levels of miR-33a and Pim-3 was significant in human pancreatic cancer tissues (Spearman's $r=-0.236, P=0.015$ ). D. The negative correlation between the plasma miR-33a levels and tumor tissue Pim-3 expression in 106 PDAC patients (Spearman's $r=-0.402, * * * P<0.001$ ). The ends of the whiskers represent the $1^{\text {st }}$ and $99^{\text {th }}$ percentiles. E. Comparison of the relative expression levels of miR-33a in plasma samples from 100 healthy controls (Normal) and 106 PDAC patients with low $(n=48)$ or high $(n=58)$ Pim-3 expression. The expression levels of miR-33a were determined by qRT-PCR and normalized to those of cel-miR-39. The horizontal line represents the median value, and the error bars indicate the SEM. ANOVA was used to determine statistical significance. ${ }^{*} P<0.01 ;$ n.s., not significant. 
above results, stable expression of Pim-3 upregulated the levels of phospho-AKT, phospho-Gsk-3 $\beta$, and $\beta$-catenin in MiaPaca-2 cells, whereas silencing of endogenous Pim-3 expression by stable transfection of PCI55 cells with a Pim-3-specific shRNA reduced the expression levels of these proteins markedly (Figure 6E). Pim and AKT kinases phosphorylate similar substrates and mediate a number of overlapping pathways [18, 26, 27]. Hence, we hypothesized that, like AKT [28], Pim-3 may also phosphorylate Gsk-3 $\beta$ to upregulate $\beta$-catenin expression. Immunoprecipitation experiments revealed that Pim-3 bound to Gsk-3 $\beta$ and phospho-Gsk-3 $\beta$ in PCI55 cells (Figure 6F), indicating a potential AKT-independent effect of Pim-3 on the $\beta$-catenin pathway.

Notably, resistant cells expressed high levels of Pim-3 protein (Figure $6 \mathrm{G}$ ). In line with previous reports $[29,30]$, we found that the AKT/ $\beta$-catenin signaling was activated in gemcitabine-resistant pancreatic cancer cells, and that overexpression of miR-33a reversed the increased expression of $\beta$-catenin by inhibiting Pim-3/AKT/ $\beta$-catenin signaling (Figure 6G). Together with the fact that miR-33a induces the downregulation of $\beta$-catenin directly [31], or indirectly by regulating Pim-3/AKT/Gsk-3 $\beta$ (Figure $6 \mathrm{E}$ and $6 \mathrm{~F}$ ), these results reveal that the negative correlation between miR-33a expression and $\beta$-catenin expression determines gemcitabine resistance.

\section{DISCUSSION}

The results of the in vitro and in vivo assays presented herein demonstrate that miR-33a downregulates the proto-oncogene encoding Pim-3 kinase. To the best of our knowledge, this is the first study to (i) demonstrate that plasma miR-33a levels could be a valuable biomarker and an important prognostic factor for human pancreatic cancer; (ii) provide evidence that miR-33a synergistically increases the sensitivity of PDAC cells to gemcitabine; (iii) identify Pim-3 as a direct binding target of miR-33a; and (iv) demonstrate that miR-33a downregulates Pim-3 to inhibit tumor growth and chemoresistance, in part via the AKT/Gsk-3 $\beta / \beta$-catenin signaling cascade, in pancreatic cancer.

Circulating miRNAs enable communication between normal cells and cancer cells [32, 33], and plasma miRNA levels may reflect clinical information correlated to tumors. The data presented herein highlight the potential clinical utility of plasma miR-33a levels as a valuable biomarker that reflects the expression of miR-33a in human pancreatic cancer tissues. MiRNAs are key components of tumorigenesis, and they participate in many cellular processes, including cell proliferation and differentiation [9]. Here, we found that miR-33a suppressed both the proliferation and growth of pancreatic cancer cells. Overexpression of miR-33a was inversely correlated with both the number and size of the tumors.
These observations provide the missing experimental evidence for the tumor-suppressive effect of miR-33a in human pancreatic cancer.

MiR-33a induces cisplatin-resistance in osteosarcoma cells by downregulating the transcription factor, TWIST [34]. By contrast, the results presented herein indicate that the level of miR-33a expression was significantly lower in gemcitabine-resistant cells than in parental cells. Therefore, it is possible that the gemcitabine-sensitizing effect of miR-33a is a cell- or tissue-specific phenomenon. Although miRNA expression is regulated by a number of stimuli [35], the mechanism by which miR-33a expression is inhibited after gemcitabine treatment remains unknown.

Our previous study indicated that Pim-3 is important for cell growth, apoptosis, and cell-cycle progression in human pancreatic cancer [16], although miR-124 targets Pim-3 in glioblastoma stem cells [36]. However, little is known about other miRNAs that target this kinase. The Pim kinase family consists of three members, namely, Pim-1, Pim-2, and Pim-3, which exhibit marked sequence similarity, especially within their kinase domains. Notably, a number of miRNAs regulate Pim-1 kinase [37], and bioinformatics analyses revealed that some of these miRNAs may also bind Pim-3. Based on these analyses, miR-33a was identified and confirmed as a novel miRNA that directly binds to Pim-3. The miR-33a target sequence within the 3'UTR of Pim-3 is evolutionarily conserved, suggesting that it plays an important functional role. Moreover, stable expression of miR-33a in pancreatic cancer cells led to a significant downregulation of Pim-3 protein expression and inhibited cancer cell growth both in vitro and in vivo. Furthermore, we previously showed that human pancreatic cancer cells express much lower levels of Pim-1 and Pim-2 mRNA than Pim-3 mRNA [38]. Thus, it is likely that miR-33a inhibits cell growth mainly by binding to Pim-3 in human pancreatic cancer cells.

A recent study showed that Pim-3 is involved in acquired gemcitabine resistance [18], and that it is a positive regulator of cell survival that increases the threshold for drug-induced apoptosis by upregulating the expression of survival proteins. Consistent with this, we found that miR-33a targeted Pim-3 to increase the chemosensitivity of pancreatic cancer cells and reverse the chemoresistance of pancreatic cancer cells to gemcitabine both in vitro and in vivo. High Pim-3 expression correlated with a poor prognosis, and plasma miR-33a levels were negatively correlated with the levels of Pim-3 in pancreatic tumors. Therefore, early examination of miR-33a expression in the plasma and Pim-3 expression in tissues may aid the development of new therapeutic strategies and predict the prognosis of pancreatic cancer. However, preclinical and clinical studies with large sample sizes and longer follow-up times are required to confirm the utility of these potential biomarkers. 
A

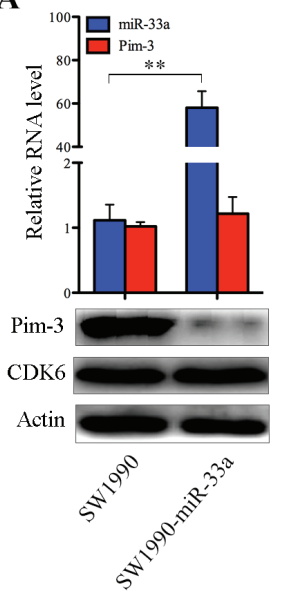

C

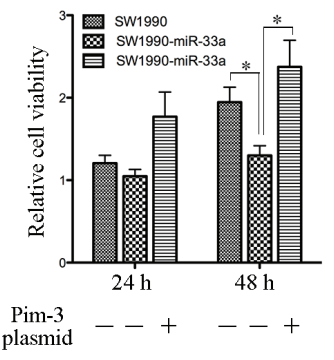

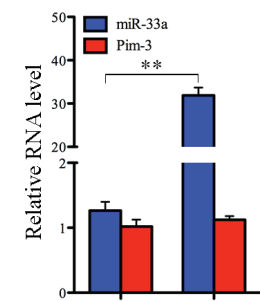

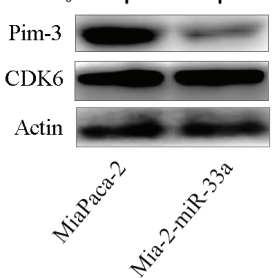

B

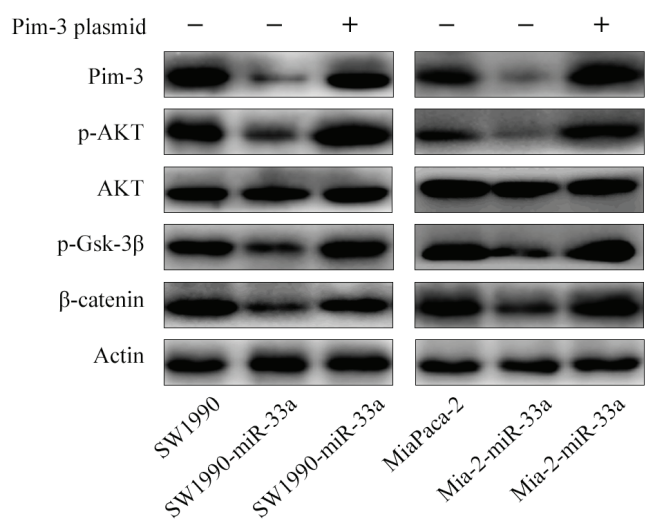

D

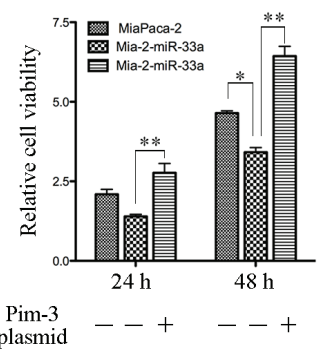

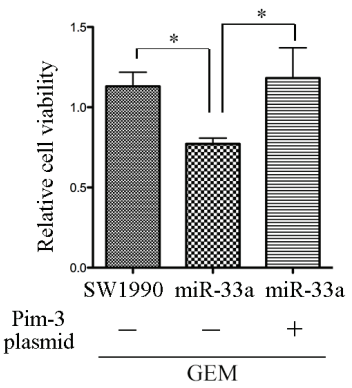

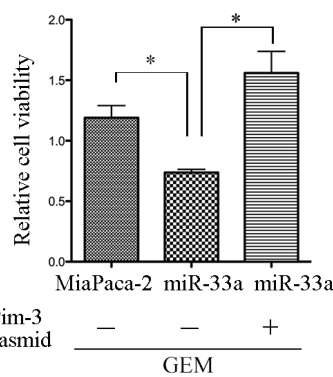

E

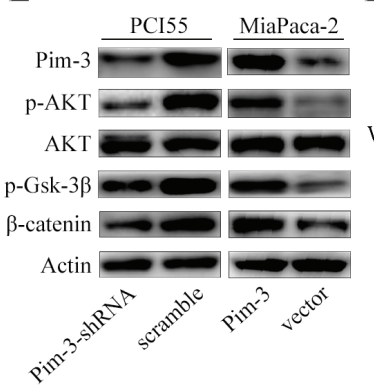

F

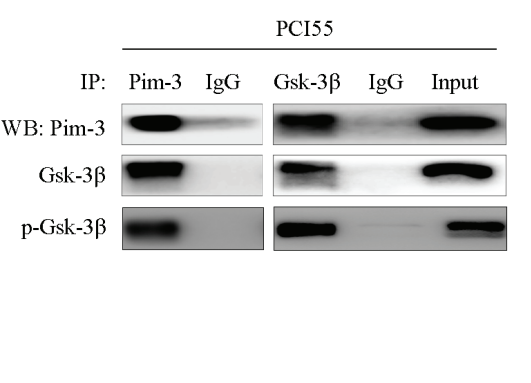

G

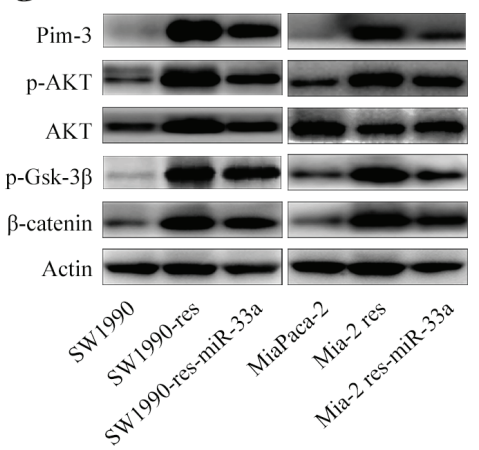

Figure 6: Downregulation of Pim-3 kinase by miR-33a inhibits cell proliferation and chemosensitivity, in part by

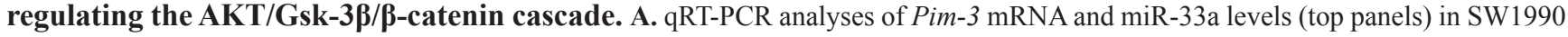
and MiaPaca-2 cells with or without stable expression of exogenous miR-33a. Data are expressed as the mean $+/-$ SD of three independent experiments. ${ }^{* *} P<0.01$. Bottom panels show western blotting of lysates from SW1990 and MiaPaca-2 cells stably expressing miR-33a and the corresponding parental cells with the indicated antibodies. B. Western blotting of lysates from SW1990 and MiaPaca-2 cells stably expressing miR-33a and their parental cells with the indicated antibodies. The cells were transiently transfected with or without a pcDNA4Pim-3 expression vector. C. Viability of SW1990 and MiaPaca-2 cells stably expressing miR-33a and that of their parental cells. The cells were transiently transfected with or without a pcDNA4-Pim-3 expression vector. The results are expressed as the mean +/- SD of five replicates from three independent experiments. ${ }^{*} P<0.05$ and $* * P<0.01$. D. The effects of GEM on the viability of SW1990-miR-33a and Mia-2-miR-33a cells and that of their parental cells, which were transiently transfected with or without a pcDNA4-Pim-3 expression vector. The cells were treated with GEM [200 nM for SW1990 cells (left panel) and $350 \mathrm{nM}$ for MiaPaca-2 cells (right panel)] for $48 \mathrm{~h}$. The results are expressed as the mean $+/-\mathrm{SD}$ of five replicates from three independent experiments. ${ }^{*} P<0.05$ and ${ }^{* *} P<0.01$. E. Western blot analyses of lysates from PCI55 cells stably transfected with Pim-3-specific or scrambled shRNA and MiaPaca-2 cells stably transfected with the pMEI-5-Pim-3 expression vector or an empty vector. Blots were probed with the indicated antibodies. F. Co-immunoprecipitation of endogenous Gsk-3 3 and Pim-3 in PCI55 cells. Lysates were obtained from PCI55 cells and used as an input control. The lysates were subjected to immunoprecipitation and western blot analyses with the indicated antibodies. G. Immunoblot analysis of the indicated proteins and phospho-proteins (p-) in lysates of SW1990 and MiaPaca-2 parental cells, GEM-resistant cells, and GEM-resistant cells stably expressing miR-33a. 
MiR-33a inhibited the Pim-3 kinase-mediated AKT/ Gsk-3 $\beta / \beta$-catenin pathway in pancreatic cancer cells. Similarly, a previous study showed that hepatocarcinoma cancer cells overexpressing miR-33a display reduced AKT phosphorylation, which affects insulin signaling [39]. By contrast, Li's group showed that miR-33a promotes the TGF- $\beta 1$-induced phosphorylation of AKT in hepatic stellate cells, which activates the cells to produce excess extracellular matrix, leading to liver fibrosis [40]. This discrepancy may be explained by the fact that a single miRNA can target multiple genes; these target genes may differ in specific cells to enable the control of different signaling pathways [37]. Because Pim-3 mRNA and protein is barely detectable in normal hepatocytes [16], miR-33a may fail to target this kinase and inhibit cell proliferation in hepatic stellate cells, which are the primary mesenchymal cells in the liver. Instead of an anti-tumor effect, the major role of miR-33a in normal cells may be to regulate lipid metabolism and/or fibrosis. By contrast, the anti-tumor effects of miR-33a might be dominant in cancer cells displaying AKT activation. MiR-33a is an essential regulator of cholesterol and lipid metabolism [41]. Hence, the findings presented here expand the biological functions of miR-33a and improve our current understanding of the relationship between metabolism and carcinogenesis.

Pim-3 can promote cell proliferation and increase gemcitabine resistance by activating $\mathrm{AKT} / \beta$-catenin signaling. Several lines of evidence implicate Pim-3 in activating STAT3 $^{\mathrm{Tyr} 705}$ and $\mathrm{Bad}^{\mathrm{Ser} 12}$ phosphorylation, which leads to the expression of a number of antiapoptotic proteins, including Bcl- $\mathrm{X}_{\mathrm{L}}$ and survivin $[16,42]$. Moreover, activating STAT3 increases the transcription of Hif- $1 \alpha$, thereby upregulating the expression of the MDR1 (P-glycoprotein) gene, resulting in reduced chemosensitivity [43, 44]. Furthermore, other groups

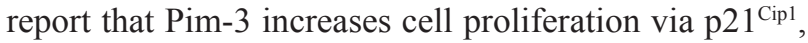
p27 Kip1, and Cdc25C [38, 45]. Here, we found that Pim-3 stabilized and promoted the accumulation of cytoplasmic $\beta$-catenin, which upregulates cyclin D1 to promote cellcycle progression, and upregulates the expression of survivin to inhibit apoptosis [46]. Notably, the MDRl gene acts downstream of $\beta$-catenin [47], suggesting that Pim-3 may contribute to MDR1 expression and gemcitabine resistance by upregulating $\beta$-catenin. Overall, we found that Pim-3 upregulated the levels of phosphoAKT, phospho-Gsk-3 $\beta$, and $\beta$-catenin in gemcitabineresistant cells; all of these molecules are associated with gemcitabine resistance [47-49]. AKT/Gsk-3 $\beta / \beta$-catenin signaling is a component of the Wnt signaling pathway, which is involved in epithelial-mesenchymal transition [50]. Therefore, we hypothesize that Pim-3 might also induce epithelial-mesenchymal transition to mediate drug resistance.

Taken together, the results reported herein show that miR-33a is a potent tumor suppressor in the pancreas and that its growth inhibitory effects are mediated, at least in part, via downregulation of the Pim-3 proto-oncogene. Loss of miR-33a expression, leading to the induction of Pim-3 expression, appears to be a critical event in the development of gemcitabine resistance.

\section{MATERIALS AND METHODS}

\section{Human tissues and cell culture}

A total of 106 human primary pancreatic adenocarcinoma tissues were collected between 2010 and 2012 at Fudan University Shanghai Cancer Center. The samples were immediately snap-frozen in liquid nitrogen and histologically examined in a timely manner. All samples were obtained with informed consent, and the project was approved by the Clinical Research Ethics Committee of Fudan University Shanghai Cancer Center.

The PCI35 and PCI55 human pancreatic carcinoma cell lines were a gift from Professor Mukaida Naofumi (Kanazawa University, Kanazawa, Japan). The SW1990, MiaPaca-2, PANC-1, BxPC-3, and Capan-1 human pancreatic carcinoma cell lines were purchased from the American Type Culture Collection (ATCC). SW1990 and Capan-1 cells were cultured in Dulbecco's Modified Eagle's Medium (Biosera), and all other cells were maintained in RPMI 1640 (Biosera). All media were supplemented with 10\% FBS (Biosera), and the cells were cultured at $37^{\circ} \mathrm{C}$ in an incubator containing $5 \% \mathrm{CO}_{2}$. The cell lines were authenticated by DNA profiling of short tandem repeats and amelogenin (Beijing Microread Genetics Co. Ltd.).

\section{Isolation of plasma miRNA}

Before extracting miRNA, $5 \mu \mathrm{l}$ of $200 \mathrm{pM}$ cel-miR-39 mimics (RiboBio, Guangzhou, China) were added to $200 \mu \mathrm{l}$ of plasma as an external standard. MiRNA was extracted from plasma using the miRcute miRNA isolation Kit (Tiangen Biotech Co. Ltd.), according to the manufacturer's instructions. Subsequently, the miRNA was reverse transcribed prior to use in quantitative reverse transcription PCR (qRT-PCR). The relative expression of target miRNA was analyzed by the $\Delta \mathrm{Ct}$ method.

\section{Real-time qRT-PCR}

qRT-PCR was performed as described previously [38]. Detailed information is provided in the Supplementary Materials and Methods.

\section{Locked nucleic acid in situ hybridization}

Locked nucleic acid in situ hybridization analyses of PDAC tissues were performed using a human miR-33aspecific double digoxigenin-labeled locked nucleic acid probe (Exiqon). Briefly, following deparaffinization and 
rehydration, tissue sections were treated with proteinase $\mathrm{K}$ at $37^{\circ} \mathrm{C}$ for $15 \mathrm{~min}$ and dehydrated through a graded series of ethanol solutions (70-100\%). The slides were then incubated at $50^{\circ} \mathrm{C}$ overnight with a digoxigeninlabeled probe diluted to $250 \mathrm{nM}$ in hybridization buffer. After stringent washes with $5 \times, 1 \times$, and $0.2 \times$ SSC buffers at $50^{\circ} \mathrm{C}$ for $30 \mathrm{~min}$, the slides were blocked with blocking reagent (Roche) at $37^{\circ} \mathrm{C}$ for $30 \mathrm{~min}$ and then incubated with alkaline phosphatase-conjugated anti-digoxigenin at $37^{\circ} \mathrm{C}$ for $30 \mathrm{~min}$. Colorimetric detection was performed by incubating the slides with 4-nitro-blue tetrazolium and 5-bromo-4-chloro-30-indolylphosphate substrate (Roche) at $37^{\circ} \mathrm{C}$ for $120 \mathrm{~min}$, followed by nuclear fast counterstain for $20 \mathrm{~min}$. The tissue sections were examined in a blinded manner by a second individual. Scoring was based on the intensity of hybridization, which was designated as 0 (negative), 1 (weak), 2 (intermediate), or 3 (strong), and the percentage of positive cells, which was designated as $0(<1 \%), 1$ (focal, $1-30 \%$ ), or 2 (diffuse, $>30 \%$ ). The following expression levels were based on the score obtained by multiplying the positivity and intensity scores: 0 , negative $(-) ; 1-3$, weakly positive $(+)$; 4-6, moderately positive $(++)$; and $>6$, strongly positive $(+++)$.

\section{Cell viability and cell cytotoxicity assays}

Cell viability and cell growth inhibition were determined using Cell Counting Kit-8 (Dojindo Laboratories), according to the manufacturer's instructions. Detailed information is provided in the Supplementary Materials and Methods.

\section{Tumor formation assay in a nude mouse model}

Eighty female BALB/c nude mice (5-weeks-old; $15-25 \mathrm{~g})$ were randomly divided into eight groups. The left flank of each mouse was inoculated subcutaneously with $2 \times 10^{6}$ MiaPaca (Mia)-2, Mia-2-miR-33a, Mia-2-res, or Mia-2-res-miR-33a cells, or with $3 \times 10^{6}$ SW1990, SW1990-miR-33a, SW1990-res, or SW1990-res-miR-33a cells. Seven days later, each group was randomly divided into two subgroups (five mice per subgroup) and subjected to intraperitoneal injection of gemcitabine $(20 \mathrm{mg} / \mathrm{kg})$ or PBS (100 $\mu \mathrm{l}$; negative control) every 4 days. Tumor growth was measured twice per week using calipers. Tumor volume was calculated using the following formula: (length $\times$ width $\left.^{2}\right) / 2$. At Day 35 post-tumor cell injection, the tumor tissues were removed and subjected to immunohistochemical and western blot analyses. The study was performed in strict accordance with the recommendations in the Guide for the Care and Use of Laboratory Animals of Fudan University. The protocol was approved by the Committee on the Ethics of Animal Experiments of Fudan University [permit number: SYXK (Hu) 2009-0082].

\section{Development of gemcitabine-resistant MiaPaca-2 and SW1990 cells}

MiaPaca-2 and SW1990 cells were serially subcultured for 9 months in medium containing incrementally increasing concentrations of gemcitabine (Sigma). The starting concentrations for the MiaPaca-2 and SW1990 cells were $0.5 \mu \mathrm{M}$ and $0.25 \mu \mathrm{M}$, respectively. Both resistant cell lines (Mia-2-res and SW1990-res) retained the capacity to proliferate when cultured in medium containing gemcitabine ( $64 \mu \mathrm{M}$ and $32 \mu \mathrm{M}$, respectively). The resistant phenotype was stable for more than 20 passages.

\section{Immunohistochemical analysis}

Immunohistochemical staining was performed as described previously [38]. Detailed information is provided in the Supplementary Materials and Methods.

\section{RNA-binding protein immunoprecipitation}

PCI55 and MiaPaca-2 cells were transfected with miR-33a or negative control (cel-miR-239b) mimics (RiboBio) using Lipofectamine 2000 reagent (Life Technologies), according to the manufacturer's instructions. At $48 \mathrm{~h}$ post-transfection, proteins were cross-linked to RNA by incubating the cells with $0.75 \%$ formaldehyde for $10 \mathrm{~min}$ at room temperature. The cells were then harvested in RNA-binding protein immunoprecipitation (RIP) lysis buffer [25 mM Tris$\mathrm{HCl}, \mathrm{pH}$ 7.5, $150 \mathrm{mM} \mathrm{KCl,} 2 \mathrm{mM}$ EDTA, 0.5\% NP40, $1 \mathrm{mM} \mathrm{NaF}, 1 \mathrm{mM}$ dithiothreitol, $100 \mathrm{U} / \mathrm{ml}$ RNasin, and $1 \times$ EDTA-free protease inhibitor (Roche Diagnostics)] and centrifuged for $15 \mathrm{~min}$. Half of the supernatant was collected in TRIzol reagent (Invitrogen) as an extract control, and the remainder was incubated with an antiArgonaute1 (AGO1) antibody (1:50; Cell Signaling Technology) at $4^{\circ} \mathrm{C}$ overnight, followed by precipitation with $50 \mu \mathrm{l}$ of protein G Sepharose4 Fast Flow (GE Healthcare Bio-Sciences AB) for $4 \mathrm{~h}$ at $4^{\circ} \mathrm{C}$. After washing the beads six times with wash buffer $[50 \mathrm{mM}$ Tris- $\mathrm{HCl}$, $\mathrm{pH} 7.5,150 \mathrm{mM} \mathrm{NaCl}, 0.05 \%$ NP40, 2 mM EDTA, $1 \mathrm{mM}$ dithiothreitol, and $100 \mathrm{U} / \mathrm{ml} \mathrm{RNasin} \mathrm{(Promega)],}$ proteinase $\mathrm{K}$ (Takara) was added, and the beads were incubated for $1 \mathrm{~h}$ at $56^{\circ} \mathrm{C}$. RNA was isolated using TRIzol reagent, and qRT-PCR was performed as described above.

\section{Construction of Pim-3 3'UTR plasmids}

The 3'UTR of Pim-3 mRNA was amplified by PCR using human genomic DNA as a template and then subcloned into the region directly downstream of the SV40 promoter-driven Renilla luciferase cassette in the psiCHECK-2 vector; this vector also contains a constitutively expressed firefly luciferase gene, which 
was used to normalize transfection efficiency. The mutant ( $\Delta$ ) 3'UTR of Pim-3, which contained a point-mutated sequence in the seed region of miR-33a, was generated from the wild-type Pim-3 3'UTR plasmid by overlapextension PCR. The structure and fidelity of the resulting constructs were confirmed by restriction mapping and sequencing. Plasmids were purified using the HighPure Maxi Plasmid Kit (Tiangen Biotech (Beijing) Co. Ltd.).

\section{Dual luciferase reporter assay}

MiaPaca-2 and PCI55 cells were seeded into 96-well plates at a density of approximately $1.5 \times 10^{4}$ cells/well and then co-transfected with miRNA mimics and the luciferase reporter construct using Lipofectamine 2000 reagent (Life Technologies). The cells were lysed in passive lysis buffer $48 \mathrm{~h}$ after transfection. The Renilla and firefly luciferase activities were quantified using the Dual Luciferase Assay System (Promega).

\section{Generation of Pim-3, Pim-3 short hairpin RNAs, and miR-33a stable cell lines}

The procedures used to generate the stable cell lines are described in the Supplementary Materials and Methods.

\section{Co-immunoprecipitation and immunoblotting}

Co-immunoprecipitation and immunoblotting were performed as described previously [38]. Detailed information is provided in the Supplementary Materials and Methods.

\section{Statistical analysis}

Group comparisons of normally distributed data were performed using $t$-tests (two sample) or one-way ANOVA (multiple comparisons). The non-parametric Wilcoxon test was used to analyze continuous nonnormally distributed data. For multiple comparisons, the Tukey-Kramer honestly significant difference was applied following ANOVA. Categorical variables were compared using $\chi^{2}$ analysis or Fisher's exact test. Kaplan-Meier analysis was used to analyze overall survival. $P<0.05$ (two-tailed) was considered significant.

\section{ACKNOWLEDGMENTS}

We would like to express our sincere gratitude to Dr. Xianghuo He (Cancer Research Institute, Fudan University Shanghai Cancer Center) for his critical comments on the manuscript. This work was supported in part by the National Science Foundation of China (NSFC) (30973476, 81272727, and 81472223), the Shanghai Pujiang Program (KW201028464), Fudan University
'985 Project' Phase III Cancer Research Projects II (985 III -YFX0102), and the Shanghai Committee of Science and Technology (12DZ2260100).

\section{CONFLICTS OF INTEREST}

The authors declare no conflict of interest.

\section{REFERENCES}

1. Siegel RL, Miller KD, Jemal A. Cancer statistics, 2015. CA Cancer J Clin. 2015; 65:5-29.

2. Li D, Xie K, Wolff R, Abbruzzese JL. Pancreatic cancer. Lancet. 2004; 363:1049-1057.

3. Burris HA, 3rd, Moore MJ, Andersen J, Green MR, Rothenberg ML, Modiano MR, Cripps MC, Portenoy RK, Storniolo AM, Tarassoff P, Nelson R, Dorr FA, Stephens CD, Von Hoff DD. Improvements in survival and clinical benefit with gemcitabine as first-line therapy for patients with advanced pancreas cancer: a randomized trial. J Clin Oncol. 1997; 15:2403-2413.

4. Bergman AM, Pinedo HM, Peters GJ. Determinants of resistance to 2',2'-difluorodeoxycytidine (gemcitabine). Drug Resist Updat. 2002; 5:19-33.

5. Andersson R, Aho U, Nilsson BI, Peters GJ, PastorAnglada M, Rasch W, Sandvold ML. Gemcitabine chemoresistance in pancreatic cancer: molecular mechanisms and potential solutions. Scand J Gastroenterol. 2009; 44:782-786.

6. Esquela-Kerscher A, Slack FJ. Oncomirs - microRNAs with a role in cancer. Nat Rev Cancer. 2006; 6:259-269.

7. Calin GA, Croce CM. MicroRNA signatures in human cancers. Nat Rev Cancer. 2006; 6:857-866.

8. Calin GA, Croce CM. MicroRNA-cancer connection: the beginning of a new tale. Cancer Res. 2006; 66:7390-7394.

9. Sun T, Kong X, Du Y, Li Z. Aberrant MicroRNAs in Pancreatic Cancer: Researches and Clinical Implications. Gastroenterol Res Pract. 2014; 2014:386561.

10. Torrisani J, Bournet B, du Rieu MC, Bouisson M, Souque A, Escourrou J, Buscail L, Cordelier P. let-7 MicroRNA transfer in pancreatic cancer-derived cells inhibits in vitro cell proliferation but fails to alter tumor progression. Hum Gene Ther. 2009; 20:831-844.

11. Ji Q, Hao X, Zhang M, Tang W, Yang M, Li L, Xiang D, Desano JT, Bommer GT, Fan D, Fearon ER, Lawrence TS, $\mathrm{Xu}$ L. MicroRNA miR-34 inhibits human pancreatic cancer tumor-initiating cells. PLoS One. 2009; 4:e6816.

12. Steele CW, Oien KA, McKay CJ, Jamieson NB. Clinical potential of microRNAs in pancreatic ductal adenocarcinoma. Pancreas. 2011; 40:1165-1171.

13. Fujii C, Nakamoto Y, Lu P, Tsuneyama K, Popivanova BK, Kaneko S, Mukaida N. Aberrant expression of serine/ threonine kinase Pim-3 in hepatocellular carcinoma 
development and its role in the proliferation of human hepatoma cell lines. Int J Cancer. 2005; 114:209-218.

14. Mikkers H, Nawijn M, Allen J, Brouwers C, Verhoeven E, Jonkers J, Berns A. Mice deficient for all PIM kinases display reduced body size and impaired responses to hematopoietic growth factors. Mol Cell Biol. 2004; 24:6104-6115.

15. Li YY, Mukaida N. Pathophysiological roles of Pim-3 kinase in pancreatic cancer development and progression. World J Gastroenterol. 2014; 20:9392-9404.

16. Li YY, Popivanova BK, Nagai Y, Ishikura H, Fujii C, Mukaida N. Pim-3, a proto-oncogene with serine/threonine kinase activity, is aberrantly expressed in human pancreatic cancer and phosphorylates bad to block bad-mediated apoptosis in human pancreatic cancer cell lines. Cancer Res. 2006; 66:6741-6747.

17. Popivanova BK, Li YY, Zheng H, Omura K, Fujii C, Tsuneyama K, Mukaida N. Proto-oncogene, Pim-3 with serine/threonine kinase activity, is aberrantly expressed in human colon cancer cells and can prevent Bad-mediated apoptosis. Cancer Sci. 2007; 98:321-328.

18. $\mathrm{Xu} \mathrm{D,} \mathrm{Cobb} \mathrm{MG,} \mathrm{Gavilano} \mathrm{L,} \mathrm{Witherspoon} \mathrm{SM,}$ Williams D, White CD, Taverna P, Bednarski BK, Kim HJ, Baldwin AS, Baines AT. Inhibition of oncogenic Pim-3 kinase modulates transformed growth and chemosensitizes pancreatic cancer cells to gemcitabine. Cancer Biol Ther. 2013; 14:492-501.

19. Jamieson NB, Morran DC, Morton JP, Ali A, Dickson EJ, Carter CR, Sansom OJ, Evans TR, McKay CJ, Oien KA. MicroRNA molecular profiles associated with diagnosis, clinicopathologic criteria, and overall survival in patients with resectable pancreatic ductal adenocarcinoma. Clin Cancer Res. 2012; 18:534-545.

20. Thomas M, Lange-Grunweller K, Weirauch U, Gutsch D, Aigner A, Grunweller A, Hartmann RK. The protooncogene Pim-1 is a target of miR-33a. Oncogene. 2012; 31:918-928.

21. Okamura K, Ishizuka A, Siomi H, Siomi MC. Distinct roles for Argonaute proteins in small RNA-directed RNA cleavage pathways. Genes Dev. 2004; 18:1655-1666.

22. Rehwinkel J, Natalin P, Stark A, Brennecke J, Cohen SM, Izaurralde E. Genome-wide analysis of mRNAs regulated by Drosha and Argonaute proteins in Drosophila melanogaster. Mol Cell Biol. 2006; 26:2965-2975.

23. Easow G, Teleman AA, Cohen SM. Isolation of microRNA targets by miRNP immunopurification. RNA. 2007; 13:1198-1204.

24. Cirera-Salinas D, Pauta M, Allen RM, Salerno AG, Ramirez CM, Chamorro-Jorganes A, Wanschel AC, Lasuncion MA, Morales-Ruiz M, Suarez Y, Baldan A, Esplugues E, Fernandez-Hernando C. Mir-33 regulates cell proliferation and cell cycle progression. Cell Cycle. 2012; 11:922-933.
25. Major MB, Roberts BS, Berndt JD, Marine S, Anastas J, Chung N, Ferrer M, Yi X, Stoick-Cooper CL, von Haller PD, Kategaya L, Chien A, Angers S, MacCoss M, Cleary MA, Arthur WT, et al. New regulators of Wnt/beta-catenin signaling revealed by integrative molecular screening. Sci Signal. 2008; 1:ra12.

26. Amaravadi R, Thompson CB. The survival kinases Akt and Pim as potential pharmacological targets. J Clin Invest. 2005; 115:2618-2624.

27. Hammerman PS, Fox CJ, Birnbaum MJ, Thompson CB. Pim and Akt oncogenes are independent regulators of hematopoietic cell growth and survival. Blood. 2005; 105:4477-4483.

28. Sarkar S, Mandal C, Sangwan R, Mandal C. Coupling $\mathrm{G} 2 / \mathrm{M}$ arrest to the $\mathrm{Wnt} /$ beta-catenin pathway restrains pancreatic adenocarcinoma. Endocr Relat Cancer. 2014; 21:113-125.

29. Shah AN, Summy JM, Zhang J, Park SI, Parikh NU, Gallick GE. Development and characterization of gemcitabine-resistant pancreatic tumor cells. Ann Surg Oncol. 2007; 14:3629-3637.

30. Guo Q, Chen Y, Zhang B, Kang M, Xie Q, Wu Y. Potentiation of the effect of gemcitabine by emodin in pancreatic cancer is associated with survivin inhibition. Biochem Pharmacol. 2009; 77:1674-1683.

31. Fang Y, Feng Y, Wu T, Srinivas S, Yang W, Fan J, Yang C, Wang S. Aflatoxin B1 negatively regulates Wnt/betacatenin signaling pathway through activating miR-33a. PLoS One. 2013; 8:e73004.

32. Lindner K, Haier J, Wang Z, Watson DI, Hussey DJ, Hummel R. Circulating microRNAs: emerging biomarkers for diagnosis and prognosis in patients with gastrointestinal cancers. Clin Sci (Lond). 2015; 128:1-15.

33. Salido-Guadarrama I, Romero-Cordoba S, PeraltaZaragoza O, Hidalgo-Miranda A, Rodriguez-Dorantes M. MicroRNAs transported by exosomes in body fluids as mediators of intercellular communication in cancer. Onco Targets Ther. 2014; 7:1327-1338.

34. Zhou Y, Huang Z, Wu S, Zang X, Liu M, Shi J. miR-33a is up-regulated in chemoresistant osteosarcoma and promotes osteosarcoma cell resistance to cisplatin by down-regulating TWIST. J Exp Clin Cancer Res. 2014; 33:12.

35. van Rooij E, Sutherland LB, Liu N, Williams AH, McAnally J, Gerard RD, Richardson JA, Olson EN. A signature pattern of stress-responsive microRNAs that can evoke cardiac hypertrophy and heart failure. Proc Natl Acad Sci U S A. 2006; 103:18255-18260.

36. Lang MF, Yang S, Zhao C, Sun G, Murai K, Wu X, Wang J, Gao H, Brown CE, Liu X, Zhou J, Peng L, Rossi JJ, Shi Y. Genome-wide profiling identified a set of miRNAs that are differentially expressed in glioblastoma stem cells and normal neural stem cells. PLoS One. 2012; 7:e36248. 
37. Liang C, Li YY. Use of regulators and inhibitors of Pim-1, a serine/threonine kinase, for tumour therapy (Review). Mol Med Rep. 2014; 9:2051-2060.

38. Zhang F, Liu B, Wang Z, Yu XJ, Ni QX, Yang WT, Mukaida N, Li YY. A novel regulatory mechanism of Pim-3 kinase stability and its involvement in pancreatic cancer progression. Mol Cancer Res. 2013; 11:1508-1520.

39. Davalos A, Goedeke L, Smibert P, Ramirez CM, Warrier NP, Andreo U, Cirera-Salinas D, Rayner K, Suresh U, Pastor-Pareja JC, Esplugues E, Fisher EA, Penalva LO, Moore KJ, Suarez Y, Lai EC, et al. miR-33a/b contribute to the regulation of fatty acid metabolism and insulin signaling. Proc Natl Acad Sci U S A. 2011; 108:9232-9237.

40. Li ZJ, Ou-Yang PH, Han XP. Profibrotic effect of miR-33a with Akt activation in hepatic stellate cells. Cell Signal. 2014; 26:141-148.

41. Rayner KJ, Suarez Y, Davalos A, Parathath S, Fitzgerald ML, Tamehiro N, Fisher EA, Moore KJ, Fernandez-Hernando C. MiR-33 contributes to the regulation of cholesterol homeostasis. Science. 2010; 328:1570-1573.

42. Chang M, Kanwar N, Feng E, Siu A, Liu X, Ma D, Jongstra J. PIM kinase inhibitors downregulate STAT3(Tyr705) phosphorylation. Mol Cancer Ther. 2010; 9:2478-2487.

43. Niu G, Briggs J, Deng J, Ma Y, Lee H, Kortylewski M, Kujawski M, Kay H, Cress WD, Jove R, Yu H. Signal transducer and activator of transcription 3 is required for hypoxia-inducible factor-1alpha RNA expression in both tumor cells and tumor-associated myeloid cells. Mol Cancer Res. 2008; 6:1099-1105.
44. Comerford KM, Wallace TJ, Karhausen J, Louis NA, Montalto MC, Colgan SP. Hypoxia-inducible factor-1dependent regulation of the multidrug resistance (MDR1) gene. Cancer Res. 2002; 62:3387-3394.

45. Isaac M, Siu A, Jongstra J. The oncogenic PIM kinase family regulates drug resistance through multiple mechanisms. Drug Resist Updat. 2011; 14:203-211.

46. Huang M, Wang Y, Sun D, Zhu H, Yin Y, Zhang W, Yang S, Quan L, Bai J, Wang S, Chen Q, Li S, Xu N. Identification of genes regulated by $\mathrm{Wnt} /$ beta-catenin pathway and involved in apoptosis via microarray analysis. BMC Cancer. 2006; 6:221.

47. Chikazawa N, Tanaka $H$, Tasaka $T$, Nakamura $M$, Tanaka M, Onishi H, Katano M. Inhibition of Wnt signaling pathway decreases chemotherapy-resistant side-population colon cancer cells. Anticancer Res. 2010; 30:2041-2048.

48. Kim MP, Gallick GE. Gemcitabine resistance in pancreatic cancer: picking the key players. Clin Cancer Res. 2008; 14:1284-1285.

49. Shimasaki $T$, Ishigaki $Y$, Nakamura $Y$, Takata $T$, Nakaya N, Nakajima H, Sato I, Zhao X, Kitano A, Kawakami K, Tanaka T, Takegami T, Tomosugi N, Minamoto T, Motoo Y. Glycogen synthase kinase 3beta inhibition sensitizes pancreatic cancer cells to gemcitabine. J Gastroenterol. 2012; 47:321-333.

50. Cong N, Du P, Zhang A, Shen F, Su J, Pu P, Wang T, Zjang J, Kang C, Zhang Q. Downregulated microRNA200a promotes EMT and tumor growth through the wnt/beta-catenin pathway by targeting the E-cadherin repressors ZEB1/ZEB2 in gastric adenocarcinoma. Oncol Rep. 2013; 29:1579-1587. 